Trivium: Estudos Interdisciplinares, Ano XIII, Ed. 2. p. 120-123.

http://dx.doi.org/10.18379/2176-4891.2021v2p.120

\title{
O que os mortos têm para nos dizer?
}

\section{What do the dead have to tell us?}

Qu'est-ce que les morts ont à nous dire ?

Cintia da Silva Lobato Borges*

Resenha do livro de Eduardo Rodrigues Peyon, Os Portões do Cemitério: Um Ensaio sobre a Coragem para Mudar o nosso Mundo. Rio de Janeiro: Vermelho Marinho, 2020.

Eduardo Peyon, no subtítulo de seu livro, define-o como um "Ensaio". Seria um ensaio sobre um mundo (im)possível? Bem, neste formato o autor articula seu conhecimento de Psicanálise, campo no qual transita há mais de vinte anos, com a poesia, que marca sua produção, com a reflexão epistemológica crítica e com temas atuais como a propalada epidemia de depressões e a mudança climática na Terra. Cumpre dizer que a perspectiva psicanalítica atravessa o livro, mas saindo da esfera puramente clínica para refletir a Cultura contemporânea, com base numa espécie antropologia psicanalítica. Eduardo apresenta, desde o início, uma ideia central, a qual sustenta as complexas articulações que ele vai tecendo ao longo do ensaio: o ser humano contemporâneo, capturado pelas promessas de prazer imediato, senhor e escravo de suas fantásticas tecnologias, não sabe mais se relacionar com a morte e nem com os mortos. Essa perda de um aparato

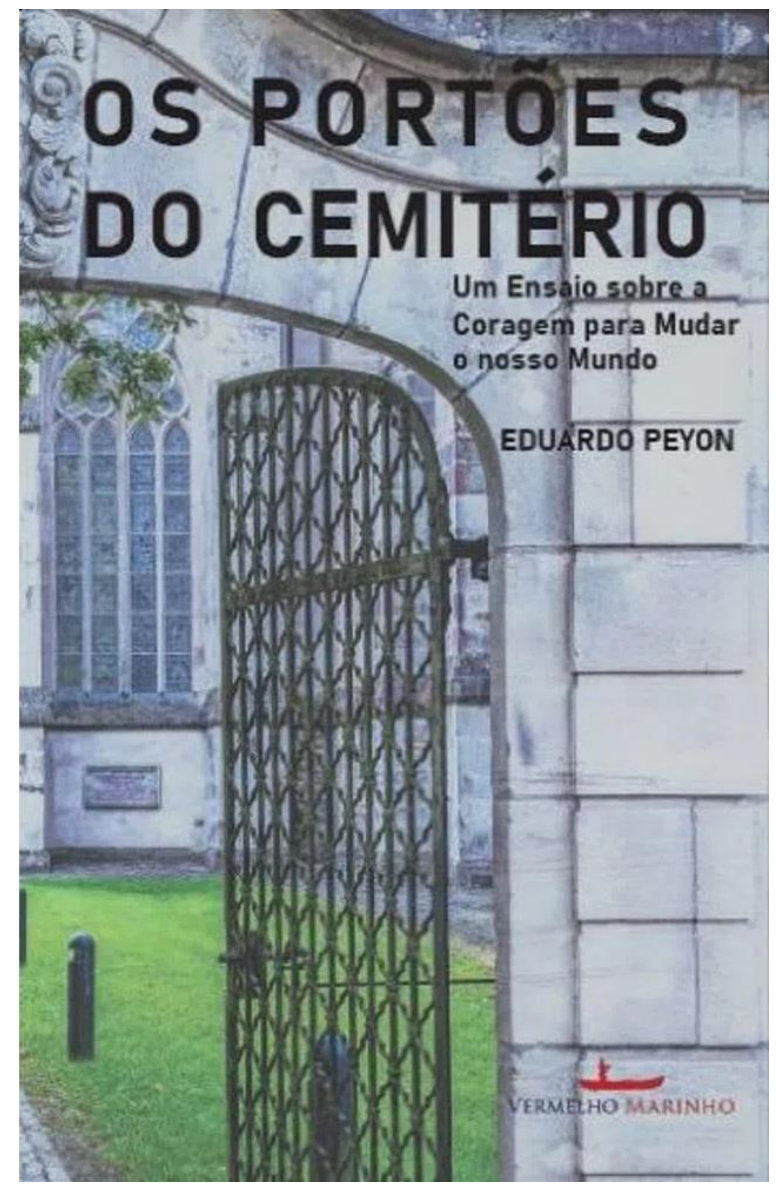
simbólico-reflexivo sobre a morte e de uma memória histórica e familiar em relação aos mortos norteia o livro, que justamente se inicia com algumas poesias sobre a morte e os mortos, chegando até o Epílogo final, no qual o autor almeja plantar as sementes do que nomeia, ao longo do texto, como "pensamento vivo": um pensamento capaz de romper com a inércia de um modelo de progresso único e cada vez mais destrutivo não apenas da vida, mas do pensar em sua pluralidade. O pensamento vivo seria, penso poder

* Psicanalista. Pesquisadora-Colaboradora Sênior (Universidade de Brasília - UNB).

ORCID ID: https://orcid.org/0000-0002-7725-3394

E-mail: cintialobato@yahoo.com.br 
resumir nesses termos, a ruptura com um predomínio da técnica sobre a ética, do consumo sobre o trabalho.

Como interlocutora do autor no período de elaboração do livro, tive a oportunidade de escutar dele, em conversa informal, alguns pensamentos que certamente o estavam atravessado ao longo da escrita de Os Portões do Cemitério. Em certa ocasião, ele me disse, muito angustiado, que o mundo estava acabando: "nós estamos destruindo o planeta, Cíntia! Estamos fazendo tudo errado. Nós vamos extinguir a humanidade, daqui a 100 anos não haverá mais nenhum ser humano sobre a Terra!" Escutar alguém bastante racional e sério dizer isso com grande aflição tocou-me profundamente. Lendo-se o livro, fica nítida a perspectiva do autor segundo a qual somos nós, de fato, os destruidores da Terra, a cada dia ao escolhermos covardemente a paralisia, a preguiça do pensamento e a alienação diante do mal que se manifesta em nosso cotidiano. A pobreza de muitos, a riqueza de poucos, o racismo, a discriminação, a política de morte, a devastação das nossas florestas, o consumismo desenfreado, a superficialidade, a falta de ética, as injustiças, a opressão e a morte. Foi a angústia diante desse destino, catalisada ao longo da escritura do livro pela eclosão da pandemia de Covid-19, que mobilizou o autor em busca não apenas de compreensão, mas de caminhos de transformação, quiçá de caminhos revolucionários.

As grandes revoluções da história humana sempre estiveram, de algum modo, ligadas à arte e aos livros, e foram feitas de construções coletivas atravessadas por ideias e pensamentos. As palavras têm um poder transformador, não podemos negar. Elas podem mudar nossos pequenos mundos - e a Psicanálise é testemunha diária do poder da fala nas transformações dos nossos sentimentos, pensamentos, sintomas etc.- e podem mudar também querelas e situações complexas globais, quando saem da boca de quem tem poder e influência para tanto. Assim, como então sair da inação à ação? $\mathrm{O}$ que de concreto podemos fazer, diante da nossa pequenez, para transformar as coisas ao nosso redor?

O Eduardo propõe possibilidades e elas começam pelo caminho da reflexão, do pensamento - "qualquer revolução é antes de tudo uma revolução do pensamento" - e da nossa relação com o tempo e com os mortos - "é com esse absoluto estranho que é a morte que precisamos aprender". Precisamos chorar nossos mortos e viver nossos lutos, porque só assim mudaremos nosso olhar sobre a vida. E que momento mais propício - e mais doído - para falar/escrever sobre isso do que o hoje, no meio de uma pandemia que já arrancou da vida tantos e tantos? Cada uma dessas vidas ceifadas era de uma pessoa que tinha uma história, tinha seus amores, esperanças e projetos. E tudo isso acabou. São esses mortos que precisamos chorar. E tantos mortos, e tantas mortes simbólicas que passaram pela nossa história.

Para reconstruirmos uma relação com nossos mortos, a primeira mudança proposta pelo autor diz respeito ao nosso modo de experenciar o tempo, especialmente o tempo dos lutos. É preciso um tempo vazio para pensarmos no nosso vazio. E é aí que ele nos propõe o que chama de uma revolução na nossa relação com o tempo. Sair do tempo do capitalismo, do 'time is money', para o kairós, o tempo oportuno e necessário a cada processo, e isso é muito subjetivo. Uma hora para um, um dia para outro, um ano para muitos, qual o sentido de tentar encaixar nossos sentimentos e nossas vivências dentro de medidas de tempo padronizadas? A revolução passa também por uma acolhida da nossa singularidade. Parar de lutar contra o tempo, e poder respirar lentamente os detalhes do viver que a correria do cotidiano nos rouba.

Nessa empreitada, o autor adentra alguns temas com os quais busca demonstrar a falência do modelo atual de sociedade, para além da dinâmica do tempo, mas sem perder de vista esse elemento estrutural da nossa existência. Dialogando com autores 
como Simone Weil, Axel Honneth, Richard Sennet e Christophe Dejours, ele interroga as formas contemporâneas de organização do trabalho, que geram efetivamente uma enorme produção, mas concentrando cada vez mais a renda, alienando os trabalhadores de uma relação significativa com o trabalho e transformando a todos em produtoresconsumidores, submetidos pelo império da "gestão pelos números", como nomeia o jurista francês Alain Supiot.

A questão do pensamento único também é debatida pelo autor. Neste tema, ele dialoga com Boaventura de Sousa Santos e o conceito elaborado por este de "plantation epistemológica", isto é, o colonialismo dos modos de pensar e de produzir conhecimento. Com respeito a este ponto, ainda que de forma secundária, Eduardo tece relações entre o modo epistemológico dominante e a forma como as culturas originárias e africanas foram submetidas na formação cultural do Brasil. Ao longo do livro, percebe-se nitidamente o incômodo do autor com o avanço da extrema direita no campo político-social brasileiro, e o livro traz em algumas importantes notas de rodapé, reflexões aguçadas sobre o Brasil. Nesse sentido, ainda que trabalhando com conceitos e análises bastante fortes, o autor faz pontes com o contexto atual propondo reflexões inovadoras.

O tema das depressões é outro pilar importante no trabalho. A partir das reflexões de Maria Rita Kehl na sua excelente obra $O$ Tempo e o Cão, Eduardo sustenta que a depressão não deve ser compreendida apenas como um fenômeno neuropsicológico, ou mesmo psicológico, mas como um complexo sociopolítico. Em sua perspectiva, o sujeito deprimido estaria em desacordo com a lógica exploratória do capitalismo neoliberal, porém estaria aprisionado entre uma "heteronomia insuportável e a autonomia impossível", exausto e sem condições de falar seu desejo. Deprimir-se seria, nesta leitura, a possibilidade de começar a pensar verdadeiramente, escapando da lógica massiva de produção-consumo do Neoliberalismo e, quem sabe, encontrando um outro modo de habitar a vida.

Por fim, o autor afirma que a Mãe-Terra não suporta mais nosso sistema produtivo-destrutivo. Alia-se a Aílton Krenak para dizer que a vida não é útil e que habitar a Terra não tem nada a ver com fabricar insólitas geringonças. É nesse ponto do texto, que Eduardo insere uma singela poesia intitulada "Freud contra o Tempo Atual", que nos derruba de vez do pedestal arrogante e narcisista em que nos encontramos, ou nos encontrávamos, antes que um novo vírus nos lembrasse da nossa pequenez, desamparo e efemeridade. O Ensaio pelo qual o autor propõe mudar o "nosso mundo", na primeira pessoa do plural, de alguma forma sublinha que essa mudança depende de cairmos desse lugar tão poderoso e assim reconhecermos a nossa finitude e uma relação de mais humildade com as demais formas de vida existentes na Terra, entendida como um complexo ser vivo do qual fazemos parte e estamos longe de dominar ou de poder dispor como bem entendemos.

Os Portões do Cemitério constitui-se, por fim, como um convite mesmo à ação coletiva, de resistência, de recusa, de mudança de contextos sociais, mudanças que são a soma das ações de cada um. Parar de seguir como rebanho diante dos mandos e desmandos de um Capitalismo supostamente vibrante e triunfante, e assumirmos as rédeas da nossa própria história como sujeitos e como sociedade. Sair da depressão diante da vida - de quem sente o peso da existência e se dobra, se rende, se acovarda - e partir para a opressão à vida, um convite a agir, a atuar sobre a vida, oprimindo-a com minhas ideias, meu desejo e minha construção simbólica. Qualquer leveza existencial verdadeira hoje passa, antes de tudo, por essa capacidade de se angustiar, de atravessar literalmente o vale da morte (mortes reais e mortes simbólicas da nossa própria história) e de lá emergir com potência de vida, o velho Conatus de Espinosa. O autor acredita 
que livros podem contribuir para o germinar de um pensamento vivo e para a construção de uma sociedade distinta da atual. Eu também!

Será uma utopia acreditar ainda em um pensamento vivo?

Citação/Citation: Borges, C. S. L. (2021). O que os mortos têm para nos dizer?. Trivium: Estudos Interdisciplinares (Ano XIII, Ed.2), pp. 120-123.

Recebido em: 14/06/2021

Aprovado em: 12/08/2021

Trivium: Estudos Interdisciplinares, Ano XIII, Ed. 2. p. 120-123. 